\title{
Induction of a primary human cytotoxic T-lymphocyte response against a novel conserved epitope in a functional sequence of HIV-1 reverse transcriptase
}

\author{
Sjoerd H. van der Burg*†, Michèl R. Klein ${ }^{*}$, Cornelis J.H. van de Velde ${ }^{\dagger}$, \\ W. Martin Kast*, Frank Miedema ${ }^{\ddagger}$ and Cornelis J.M. Melief*
}

\begin{abstract}
Objective: To identify novel major histocompatibility complex (MHC) class I-restricted cytotoxic T-lymphocyte (CTL) epitopes conserved in HIV-1.

Methods: Potential conserved CTL epitopes were selected using a predictive computer algorithm based on a human leukocyte antigen (HLA)-A*0201 peptide-binding motif and tested for actual binding to the human processing defective cell line 174.CEM T2 (T2). Hence, the amina-acid sequences of 14 full-length sequenced HIV-1 strains were analysed. An in vitro primary peptide-specific human CTL response was induced with responding lymphocytes of an HIV-1-seronegative donor. Responding $T$ cells were cloned by limiting dilution and tested for their ability to recognize naturally processed antigen in a ${ }^{51} \mathrm{Cr}$-release assay using recombinant vaccinia-HIV protein-infected B-lymphoblastoid cells (B-LCL) as target cells.

Results: The analysis of peptides bearing the HLA-A*0201 motif for conservation resulted in one peptide of Env, three of Gag and 12 of Pol. Only Gag ${ }_{340-348,}$, Pol $_{83-92}$, $\mathrm{Pol}_{267-277}$ and Pol ${ }_{960-968}$ showed binding properties to T2 comparable with those of known CTL epitopes $\mathrm{Gag}_{76-84}$ SLYNTVATL and Pol $468-476$ ILKEPVHGV. A successful primary MHC class I-restricted CTL response was induced against Pol ${ }_{468-476}$ and $\mathrm{Pol}_{267-277}$ VLDVGDAYFSV, a peptide in a functional sequence of reverse transcriptase (RT). The resulting CD8+ CTL clones were peptide-specific and able to specifically lyse recombinant vaccinia-HIV-1 RT-infected HLA-A*0201-matched B-LCL.

Conclusion: The method used to screen proteins sequences for potential CTL epitopes, test selected peptides for binding to MHC class I and induction of an in vitro primary response against optimal binding peptides resulted in the identification of at least one novel conserved CTL epitope. The novel epitope is located in an area crucial for RT activity. This study demonstrates the feasibility of identifying highly conserved HIV-1-derived peptides capable of eliciting novel anti-HIV-1 CTL responses.
\end{abstract}

$$
\text { AIDS 1995, 9:121-127 }
$$

Keywords: HIV-1, cytotoxic T lymphocytes, reverse transcriptase, Gag, vaccine, primary cytotoxic T-lymphocyte induction, peptide

\section{Introduction}

Cytotoxic T-cell responses against virus-infected cells are of key importance in the clearance and control of most virus infections [1]. Cytotoxic T lymphocytes (CTL) recognize viral peptides presented by major histocompat- ibility complex (MHC) class I molecules at the surface of infected cells [2-6]. CTL responses against many viruses involve recognition of a single or few immunodominant viral epitopes [7-9]. However, studies of CTL specific for HIV-1 have shown that multiple epitopes of all proteins of HIV-1 may serve as targets and that these epi-

From the *Department of Immunohaematology and Blood Bank, the tDepartment of Surgery, University Hospital, Leiden and the ${ }^{\text {DDepartment }}$ of Clinical Viro-immunology, Central Laboratory of The Netherlands Red Cross Blood Transfusion Service, Amsterdam, The Netherlands.

Note: W. M. K. is a senior fellow of the Royal Netherlands Academy of Arts and Sciences (KNAW).

Requests to reprints to: Cornelis J.M. Melief, Department of Immunohaematology \& Blood Bank, University Hospital, PO Box 9600,2300 RC Leiden, The Netherlands.

Date of receipt: 4 July 1994; revised: 4 November 1994; accepted: 6 December 1994. 
topes can be presented by the same restricting human leukocyte antigen (HLA) class I molecule [10-13]. To date there has been no systematic study to determine to which of these peptides an HIV-seropositive individual responds. The initial vigour of the CTL response against HIV-1 in infected individuals is shown by CTL activity of freshly isolated peripheral blood mononuclear cells (PBMC) without restimulation [13]. Despite these initial CTL responses, HIV-1 infection nevertheless leads to virus persistence and eventually to deterioration of humoral and cellular immune responses [14-16], resulting in AIDS [17].

One role of CTL in eradicating HIV-infected human cells was shown in studies in which in vitro HIV-1 replication was controlled by MHC class I-restricted CTL $[18,19]$. Studies of SIV-infected macaques showed that animals with broad CTL activity were able to control disease in contrast to SIV-infected macaques with low CTL activity [20,21]. In HIV-1-infected asymptomatic individuals effective CTL responses were found against relatively or highly conserved sequences of HIV-1 Gag $[10,22,23]$, reverse transcriptase (RT) [24] and Nef [25].

HIV-1 exhibits sequence variation due to error-prone $\mathrm{RT}$, recombination and the absence of an error-correction system [26]. Consequent to this lack of control, the number of virus variants increases with disease progression [27]. In longitudinal studies a decline or loss of CTL responses to a particular epitope was found associated with the emergence of epitope-loss virus variants $[28,29]$. Also, in a comparison of CTL reactivity to an epitope of one particular HIV-1 virus with natural variants of this epitope in other HIV-1 viruses, a decrease or absence of cytotoxicity against peptide-incubated targets was observed [30]. These results combined with those of CTL studies in long term asymptomatic individuals suggest that CTL capable of controlling HIV-1 infection are directed against epitopes that are not readily prone to mutation. Strong and sustained CTL responses against these highly conserved sequences might enable the infected host to effectively control the spread of virus or to establish at least a low grade of infection so that disease progression is delayed.

Conservation of protein sequences may reflect functional importance in the life cycle of the virus. Since HLA$A \star 0201$ is found at high frequency in all human races

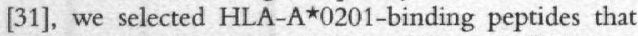
were completely conserved among different HIV-1 virus strains. In vitro induction of peptide-specific class I-restricted primary CTL responses has been achieved in the mouse [32,33] as well as in human [34] systems. We used the processing-defective cell line T2 [35] to detect binding of the selected peptides [36], and a modified strategy as described by Houbiers et al. [34] to induce primary CTL responses.

This study demonstrates that novel CTL epitopes in conserved HIV sequences can be identified by the strategy of in vitro primary immune response induction by
HLA-A ${ }^{\star} 0201$ motif-bearing peptides with proven binding ability to HLA-A*0201.

\section{Materials and methods}

\section{Cell lines and recombinant vaccinia viruses}

The processing defective T2 cell line, which expresses low levels of surface HLA-A $\star 0201$, was a gift from Dr P. Cresswell (Yale University, New Haven, Connecticut, USA). Recombinant vaccinia constructs were kindly provided by Dr B. Moss (National Institute of Allergy and Infectious Diseases, National Institutes of Health, Bethesda, Maryland, USA). The recombinant vaccinia virus vCF- 21 contains the HIV-1 1 HXB2 pol RT gene (vvRT) [37]. The negative control recombinant vaccinia virus vSC-8 contains the Escherichia coli $\beta$-gal gene (vvLacZ) [38].

Cytotoxicity of CTL against target cells was tested in a standard 4 -h ${ }^{51} \mathrm{Cr}$-release assay. HLA-A $\star^{\star 0201-p o s i t i v e ~}$ B-LCL served as target cells. B-LCL were subtyped with an HLA-A ${ }^{\star} 0201$ alloreactive CTL clone [39]. Briefly, B-LCL were either labelled for $1 \mathrm{~h}$ at $37^{\circ} \mathrm{C}$ with $100 \mu \mathrm{Ci}$ ${ }^{51} \mathrm{Cr}$ and preincubated for $10 \mathrm{~min}$ with peptide, or target cells were infected (multiplicity of infection, 5) with appropriate recombinant vaccinia constructs $16 \mathrm{~h}$ before labelling. A difference of $\geq 10 \%$ with background lysis was considered to be specific lysis of target cells. The percentage-specific ${ }^{51} \mathrm{Cr}$ release was calculated by the formula:

$$
\% \text { specific }{ }^{51} \mathrm{Cr} \text { release }=
$$

(release experimental well-background release)

(maximum release - background release)

Target cell lysis by CTL was blocked by incubation of CTL with anti-CD8 monoclonal antibody (MAb) FK18 [40]. FK18 was used as a $1: 300$ dilution of ascitic fluid. Effector cells were mixed with FK18 and preincubated for $1 \mathrm{~h}$ at room temperature. MHC class I restriction was determined by $30 \mathrm{~min}$ preincubation of $\mathrm{T} 2$ cells with anti-HLA class I MAb W6/32.

\section{Peptide selection and $\mathrm{T} 2$ peptide-binding assay}

All amino-acid sequences of 14 different full-length sequenced HIV-1 virus strains: LAI, MN, NL43, OYI, SF2, RF, MAL, D31, CAM1, HAN, ELI, NDK, JRCSF and JR-FL [41] were screened for possible HLA$A \star 0201$-restricted CTL epitopes using a scoring system [36]. Virus strains not full-length sequenced or the highly divergent Cameroonian isolates were not included. All predicted high-scoring peptides were compared and those sequences with anchor residues on both anchor positions and completely conserved among all $\mathbf{1 4}$ strains were synthesized as described previously [34].

The T2 HLA-A*0201 peptide-binding assay was performed according to Nijman et al. [36]. Fluorescence 
of viable cells was measured on a FACscan flow cytometer (Becton Dickinson, Franklin Lakes, New Jersey, USA). The fluorescence index (FI) was calculated by the formula: $\mathrm{FI}=$ (mean fluorescence sample - mean fluorescence background) $\div$ mean fluorescence background.

Peptides with a $\mathrm{FI} \geq 0.5$ were considered to bind to $H L A-A \star 0201$. Subsequent serial dilutions of the concentration of peptide were used to determine the concentration needed to upregulate HLA-A ${ }^{\star} 0201$ to half maximum fluorescence on the $\mathrm{T} 2$ cell line.

\section{Primary CTL induction}

The in vitro CTL response induction method recently published [34] was modified as follows. T2 cells were loaded with $100 \mu \mathrm{g} / \mathrm{ml}$ peptide overnight at $37^{\circ} \mathrm{C}$ and subsequently treated with $50 \mu \mathrm{g} / \mathrm{ml}$ Mitomycin-C (Kyowa Co. Ltd, Tokyo, Japan). After $2 \mathrm{~h}$ the cells were washed twice and used as antigen-presenting cells by cocultivation with HLA-A*0201-positive PBMC of a healthy HIV-1-seronegative donor at a T2-to-PBMC ratio of $1: 4$. Cells were cultured for 10 days in $2 \mathrm{ml}$ standard medium [RPMI-1640 Dutch modification (Gibco, Paisley, Scotland, UK) containing I-glutamine, antibiotics, $15 \%$ pooled human serum] and $40 \mu \mathrm{g} / \mathrm{ml}$ peptide in 24-well Costar plates (Costar, Cambridge, Massachusetts, USA) at a density of 2 million cells/well. Responder cells were harvested and depleted of CD4+ $\mathrm{T}$ cells using CD4+ magnetic beads (Dynal A.S, Oslo, Norway). Two million CD4-depleted responder cells were restimulated with a feeder-mix consisting of $1 \times 10^{6}$ irradiated (3000 rad) autologous PBMC and $2 \times 10^{5}$ irradiated $(10000 \mathrm{rad})$ autologous B-LCL. Feeder cells were sensitized with $50 \mu \mathrm{g} / \mathrm{ml}$ peptide in serum-free Iscove's modified Dulbecco's medium for $2 \mathrm{~h}$ at $37^{\circ} \mathrm{C}$, washed and added to the responders in standard medium supplemented with $60 \mathrm{IU} / \mathrm{ml}$ human recombinant interleukin-2 (rIL-2; Eurocetus, Amsterdam, The Netherlands). At day 17, responder cells were harvested on Ficoll-lymphoprep (Nycomed Pharma, Oslo, Norway) and cloned by limiting dilution. Ten or less responder cells were cocultured with $1 \times 10^{5}$ irradiated $(3000 \mathrm{rad})$ PBMC and 5000 irradiated (10000 rad), peptide sensitized washed B-LCL (from at least two different HLA-A ${ }^{\star} 0201$-positive donors) in $100 \mu$ l standard medium containing $60 \mathrm{IU} \mathrm{rIL}-2 / \mathrm{ml}$ and $1 \%$ leucoagglutinin (Phytohaemagglutinin-leucocytes; Sigma, St Louis, Missouri, USA). Growing clones were expanded but stimulated with peptide-sensitized washed B-LCL at a 2-week interval only.

\section{Results}

Selection of conserved HIV peptides with binding ability for HLA-A*0201

Analysis of binding to HLA-A ${ }^{\star} 0201$ of the amino-acid sequences of Env, Gag, Pol, Rev, Vpu, Vif, Vpr, Tat and Nef of 14 full-length HIV-1 strains resulted in one conserved peptide of Env, three of Gag, and 12 of Pol bearing the HLA-A $\star_{0201}$ motif. The binding capacity of these peptides was tested in the T2-binding assay. Five out of 16 peptides had a $\mathrm{FI} \geq 0.5$ at a concentration of $100 \mu \mathrm{g} / \mathrm{ml}$. Subsequent binding tests with serial dilutions of the peptide concentration revealed high affinity binding of one Gag peptide ( $\mathrm{Gag}_{345-353}$ ), and three Pol peptides ( Pol $_{83-92}$, Pol $_{267-277}$, Pol $960-968$; Table 1). As a control, the serial dilutions of two known CTL epitopes Pol $_{468-476}$ ILKEPVHGV [42] (highly conserved) and Gag77-85 SLYNTVATL (not conserved) [43] resulted in a half maximum of 5 and $20 \mu \mathrm{g} / \mathrm{ml}$, respectively (Table 1). In accordance with earlier studies [36], $60 \%$ of the motif-bearing peptides did not bind.

Table 1. Binding of conserved HIV-1 sequences of Gag, Pol and Env to human leukocyte antigen (HLA)-A*0201.

\begin{tabular}{|c|c|c|c|c|}
\hline Protein (position)* & $\begin{array}{l}\text { Binding } \\
\text { score }\end{array}$ & Peptides & $\mathrm{Fl}$ & $\begin{array}{l}1 / 2 \max \\
(\mu \mathrm{g} / \mathrm{ml})\end{array}$ \\
\hline Gag $(76-84)^{\dagger}$ & 576 & SLYNTVATL & 1.3 & 20.0 \\
\hline Gag (227-236) & 576 & QMREPRGSDI & 0.2 & \\
\hline Gag (235-243) & 288 & DIAGTTSTL & 0.2 & \\
\hline Gag (340-348) & 144 & EMMTACQGV & 1.0 & 10.0 \\
\hline Pol $(78-88)$ & 288 & QLKEALLDTGA & 0.4 & \\
\hline $\operatorname{Pol}(83-92)$ & 288 & LLDTGADDTV & 1.3 & 17.5 \\
\hline Pol (105-114) & 576 & KMIGGIGGFI & 0.3 & \\
\hline Pol (160-169) & 288 & PISPIETVPV & 0.5 & 62.5 \\
\hline Pol (163-171) & 576 & PIETVPVKL & 0.3 & \\
\hline $\operatorname{Pol}(267-277)$ & 288 & VLDVGDAYFSW & 2.7 & 15.0 \\
\hline $\mathrm{Pol}(307-317)$ & 288 & VLPQGWIKGSPA & 0.2 & \\
\hline Pol $(460-468)$ & 576 & ELAENREIL & 0.2 & \\
\hline $\mathrm{Pol}(468-476)^{*}$ & 2304 & ILKEPVHGV & 2.9 & 5.0 \\
\hline Pol $(580-588)$ & 288 & PLVKLWYQL & 0.1 & \\
\hline Pol (909-919) & 288 & GIGGYSAGERI & 0.2 & \\
\hline Pol (931-939) & 1152 & ELQKQITKI & 0.1 & \\
\hline Poil $(960-968)$ & 576 & ULWKGEGAV & 0.7 & 32.5 \\
\hline Env $(114-124)$ & 288 & SLKPCVKTLPL & 0.4 & \\
\hline
\end{tabular}

"Derived from HIV-1 strain JR-CSF. The peptides Pol $468-476$ [42] and $\mathrm{Gag}_{77-85}$ [43] are known HLA-A*0201-restricted cytotoxic T-lymphocyte epitopes, therefore, the half of maximum $(1 / 2 \mathrm{max})$ fluorescence values obtained with these peptides served as reference for good binding. Computer scoring of predicted HLA-A*0201-binding peptides was performed according to Nijman et al. [36]. The importance of the anchor positions was stressed by assigning 12 points to allowed residues at these positions [36]. The fluorescence index (FI) is shown at $100 \mu \mathrm{g} / \mathrm{ml}$ of peptide: peptides with a $\mathrm{FI} \geq 0.5$ were considered to be binding peptides. The affinity of binding peptides was tested by determining the peptide concentration needed to upregulate HLA-A*0201 expression on the $T 2$ cell line to $1 / 2$ max fluorescence: peptides with $1 / 2$ max $>$ two times the $1 / 2$ max of peptide $\mathrm{Gag}_{76-84}$ were considered to be weakly binding peptides.

\section{Induction of primary CTL responses}

We induced primary CTL responses against the peptides $\mathrm{Pol}_{267-277}$ and Pol468-476 (Table 1) from PBMC of a HIV-1-seronegative healthy donor. The known HLA$A \star 0201$-restricted peptide $\mathrm{Pol}_{468-476}$ was selected as a positive control for CTL induction. Limiting dilution resulted in clones $468-13,468-16$ and $468-22$ against peptide Pol $468-476$ and clone $267-18$ against peptide Pol 267-277 showing specific lysis of T2 cells sensitized with peptide (Fig. 1). 


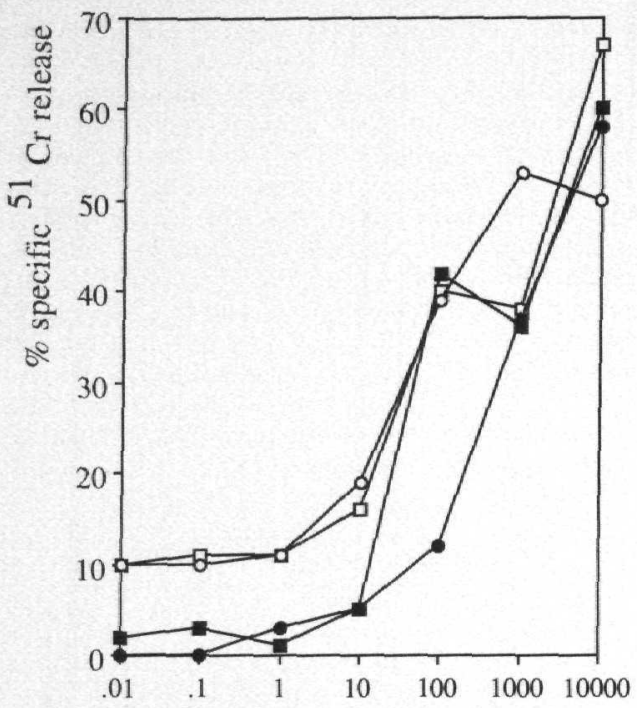

concentration of peptide, $\mathrm{pmol} / \mathrm{ml}$

Fig. 1. Lytic activity of clones 468-13 $(\square, 468-16 \square$ and 468-22 (O) obtained against peptide $\mathrm{Pol}_{468-476}$ and clone 267-18 () against peptide Pol $267-277$ was tested against peptide-loaded T2 cells. T2 cells were pre-incubated for $10 \mathrm{~min}$ with increasing concentrations $(\mathrm{pmol} / \mathrm{ml})$ of specific peptide and then used as targets. The percentage lysis of T2 cells is represented as the percentage-specific $51 \mathrm{Cr}$-release values and shows for each clone the mean of triplicate measurements at an effector-to-target ratio of $5: 1$ for Pol $_{468}-476$ and 10:1 for Pol 267-277 obtained in two independent experiments.

FACscan analysis showed that the clones were CD8-positive. Blocking studies with anti-CD8 or anti-HLA class I antibodies revealed that CTL activity was mediated by CD8+ $\mathrm{T}$ cells and was HLA class-I-restricted (data not shown).

The clones were tested at different effector-to-target cell (E:T) ratios to estimate the cytolytic capacity. At an E : T ratio of 0.015 for clone $267-18$ and 0.15 for clone $468-22, \mathrm{~T} 2$ cells sensitized with $5 \mathrm{~nm} / \mathrm{ml}$ of peptide are specifically lysed (data not shown).

The fine specificity of clone $267-18$ was studied by serine and arginine replacements in the synthetic $\mathrm{Pol}_{267-277}$ peptide. Binding of the peptide was strongly influenced by the residues at position 2 and 11 . Replacement by a small amino acid such as serine showed that residues 3,4 , 5,8 and 9 in particular are important for recognition by the CTL. Arginine replacement had more drastic effects in that only a replacement at position 6 allowed recognition of peptide-sensitized target cells (data not shown). Thus, residues at positions $3,4,5,8,9$ and 10 interfere with recognition by the $\mathrm{T}$-cell receptor.

Recombinant vaccinia virus-infected target cells To investigate whether the clones would not only recognize synthetic peptide but also the naturally processed
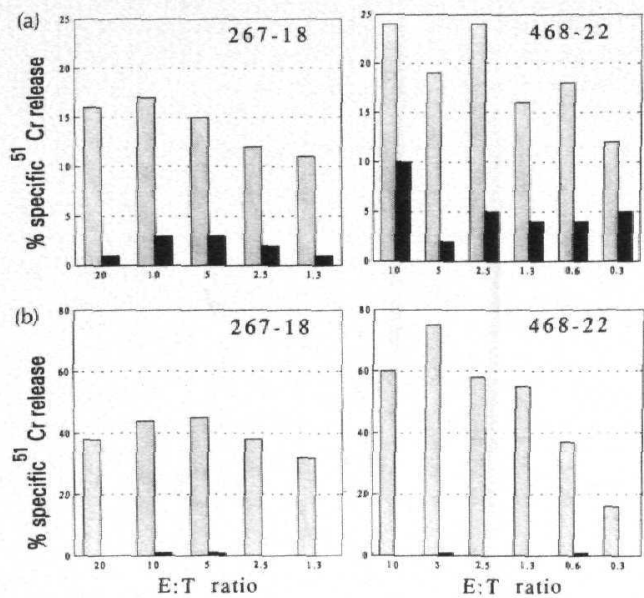

Fig. 2. Recognition of target cells sensitized by exogenously added peptide and of target cells expressing the natural processed epitope by clone 267-18 (left) and clone 468-22 (right). (a) B-lymphoblastoid cells (B-LCL) were infected with recombinant vaccinia-HIV-1 reverse transcriptase (vvRT; $D$ gene. Aspecific lysis of the B-LCL due to vaccinia infection was monitored by infecting B-LCL with recombinant vaccinia-B gal (vvLacZ; gene, (b) Aspecific lysis of the BLCL by the cytotoxic T-lymphocyte clones was also tested. The specific lysis of $5 \mu \mathrm{g} / \mathrm{ml}$ peptide-pulsed B-LCL $\square$ versus background lysis of non-peptide-pulsed B-LCL (1) is shown. The clones were tested at different effector-to-target $(E: T)$ ratios and the percentage-specific lysis of different targets is represented as percentage-specific ${ }^{51} \mathrm{Cr}$-release values and show for each clone the mean of triplicate values obtained in two independent experiments.

peptide, the most sensitive CTL clones were tested against B-LCL infected with the recombinant vaccinia viruses vvRT or vvLacZ. Clones 468-22 and 267-18 lysed vvRT but not vvLacZ-infected B-LCL (Fig. 2a). In the same experiments both clones specifically lysed peptide-sensitized HLA-A ${ }^{\star 0201-m a t c h e d ~ B-L C L ~(F i g . ~}$ $2 b)$.

\section{Discussion}

The therapeutic potential of CTL against tumours and viruses has recently been reviewed $[1,12,13,44]$. The imminent escape of HIV-1 from deteriorating humoral and cellular immune responses requests prompt and specific intervention. Evoking CTL to highly conserved HIV1-derived epitopes may decrease the risk of emerging escape mutants of HIV -1 , which may contribute to the control of HIV-1 infection.

Following our strategy to screen protein sequences for potential CTL epitopes, test selected peptides for MHC class I binding, and induce CTL against the optimally binding peptides resulted in CTL recognizing naturally processed HIV-1-derived peptides, including one novel RT epitope in a protein sequence crucial for RT activity. 
The existence of CD4+ CTL in HIV patients [45,46] is acknowledged but CD4+ T cells are more susceptible to HIV infection and compared with CD8+ CTL, display lysis of HIV-infected cells only at higher E:T ratios [45]. In vitro it is possible to infect $\mathrm{CD} 8+\mathrm{T}$ cells $[47,48]$. The in vivo relevance of this phenomenon is debatable because HIV-1 DNA was not detectable by polymerase chain reaction (PCR) in the $\mathrm{CD} 8+$ subset of PBMC from AIDS patients [49]. Therefore we have focused primarily on induction of HIV-specific CD8+ CTL.

One Gag and three Pol peptides showed similarly highaffinity binding properties as previously published HLA$A \star 0201$-restricted CTL epitopes $[42,43]$. Analysis of the Gag sequences of 70 HIV-1 isolates [50] showed the high conservation of the binding $\mathrm{Gag}_{345-353}$ peptide in 63 out of 70 isolates. It is noteworthy that CTL from a long-term asymptomatic HIV-1-seropositive individual reacted to target cells pulsed with a 20 amino-acid peptide containing this $\mathrm{Gag}_{345-353}$ peptide [15].

Induction of primary CTL responses to peptides in vitro has already been shown in mice [51] and humans $[34,52]$. Our in vitro induction protocol, using PBMC from a healthy HIV-1-seronegative blood donor, allowed generation of CTL to a novel highly conserved HLA-A*0201-restricted epitope ( $\mathrm{Pol}_{267-277}$ : VLDVGDAYFSV) derived from HIV-1 pol RT. We also elicited a primary CTL response to the already known HLA$A^{\star} 0201$-restricted epitope, published by Walker et al. $\left(\mathrm{Pol}_{468-476}\right)$ [42]. The resulting CD8 + CTL clones were able to recognize target cells pulsed with as little as 10 $\mathrm{pmol}$ peptide/ $/ \mathrm{ml}$. Observations in mice of CTL against influenza nucleoprotein showed recognition of peptide at concentrations of $0.1-100 \mathrm{pmol}$ peptide $/ \mathrm{ml}[2,3]$.

Clones 468-22 and 267-18 both directed to RT epitopes were able to specifically kill recombinant vaccinia HIV-1 RT-infected targets in a class I-restricted fashion. Although ${ }^{51} \mathrm{Cr}$ release is lower it is frequently observed that the lower peptide concentration displayed at the cell surface following endogenous processing is often associated with lower ${ }^{51} \mathrm{Cr}$-release values than following incubation with much higher doses of exogenous peptide. In a recent study from our laboratory [53], low in vitro tumour lysis values following incubation with tumour-specific CTL was nevertheless associated with CTL-mediated protection against tumour outgrowth in vivo [53]. Thus, the lower CTL response measured in vitro against the endogenously processed peptide provided adequate protection in vivo [53]. An overall difference in the maximum percentage of lysis can be noticed between clones $267-18$ and $468-22$. This could be due to a difference in lytic capability of the clones although both clones lysed their targets at similar E: T ratios. The lysis of vvRT-infected cells is similar when compared with the background lysis of vvLacZ-infected cells. On the other hand, variation in peptide affinity can exist between different CTL recognizing the same epitope $[2,3]$.
It will be of interest to study the possible diversity of the T-cell repertoire against epitope $\mathrm{Pol}_{267-277}$.

Sequences in which no variation is allowed due to functional or structural constraints on the viral protein may offer CTL an opportunity to attack HIV-1 at its Achilles' heel. The RT-derived peptide $\mathrm{Pol}_{267-277}$ may therefore be a particularly interesting epitope. Site-specific mutagenesis of the region overlapping peptide $\mathrm{Pol}_{267-277}$ revealed that alterations in the sequence by substitution of single amino acids at position 269 (asp to glu), 272 (asp to gly) or 273 (ala to ser) can profoundly affect RT activity [54]. All of these amino acids are located in peptide $\mathrm{Pol}_{267-277}$. The amino-acid replacement study showed that among six of the amino-acid side chains the aspartic acid at position 269 was also important for recognition by clone $267-18$. The amino acids at positions 3, 4, 5, 8, 9 and 10 seem essential for T-cell receptor recognition, which largely confirms previous reports on HLA-A ${ }^{\star} 0201$-restricted CTL $[8,34,55]$. Viral escape from $\mathrm{T}$-cell recognition by mutation of the T-cell receptor contact residues $[28,56]$ could be disastrous for the virus in the case of the $\mathrm{Pol}_{267-277}$ epitope.

Recently Harrer et al. [24] reported a study of antiHIV CTL responses in long-term asymptomatic HIVseropositive individuals. A response was found against a CTL epitope that spans the RT region of the highly conserved YMDD amino-acid motif also known to be important for RT function $[54,57]$. Targeting the immune response to this epitope, the epitope identified in this study and others found in regions that are functionally important for the life cycle of HIV-1 may influence the length of the asymptomatic phase.

Our data show the feasibility of primary in vitro targeting to a synthetic viral peptide of human CTL capable of recognizing the naturally processed peptide. Recently, induction of primary CTL in a completely autologous system was reported [52]. These approaches may allow in vitro culture of CTL against a viral or autologous peptide of interest for adoptive transfer into patients with viral disease or cancer. Primary CTL induction with lymphocytes obtained from HIV-infected subjects has to be established. We are currently investigating this possibility with PBMC obtained from long-term asymptomatic patients.

A study by Sijts et al. [58] in mice showed the relevance of cryptic epitopes: upon infection with the Moloney sarcoma virus-murine leukaemia virus complex $\mathrm{C} 57 \mathrm{BL} / 6$ mice $(\mathrm{H} 2 \mathrm{~b})$ respond with a class $I \mathrm{Db}_{-}$ restricted CTL response but peptide vaccination with a $\mathrm{K}^{\mathrm{b}}$-restricted epitope resulted in CTL recognizing this epitope both as synthetic peptide and as endogenously processed antigen in the context of $\mathrm{K}^{\mathrm{b}}$. It is therefore feasible to direct the cellular immune response to subdominant epitopes that are not selected as major epitopes for CTL recognition. It can be argued that immunization with peptides might result in relatively low responses in vitro and that peptide immunization might therefore result in weak responses in vivo. However, in 
vivo peptide immunization could result in higher levels of specific CTL because the proper cytokine networks and lymphoid architecture are available. In animal models it has been shown that peptide immunization can effectively protect against lymphocytic choriomeningitis virus [9], Sendai virus [7] and human papilloma virus-induced tumours [53]. A peptide-based vaccine also elicited protective CTL in rhesus monkeys against SIV [59].

The exquisite sensitivity of CTL to sequence variation in the epitope itself demonstrates the need for stable epitopes. Thus peptide vaccines should be designed to evoke immune responses against several of these functionally important epitopes in order to minimize the emergence of escape variants of the virus.

\section{Acknowledgements}

We thank Drs F. de Koning and T.H.M. Ottenhoff for critically reading this manuscript and Dr J.W. Drijfhout for synthesizing peptides.

\section{References}

1. Kast WM, Melief CIM: In vivo efficacy of virus-derived peptides and virus-specific cytotoxic T Iymphocytes. Immunol Lell 1991 30:229-232.

2. Rötzschke $\mathrm{O}$, Falk $\mathrm{K}$, Deres $\mathrm{K}$, et al: Isolation and analysis of naturally processed viral peptides as recognized by cytotoxic T cells. Nature 1990, 348:252-254.

3. Townsend ARM, Rothbard 1, Gotch FM, Bahadur G, Wraith D, McMichael Al: The epitopes of influenza nucleoprotein recog nized by cytotoxic $T$ lymphocytes can be defined with shor synthetic peptides. Cell 1986, 44:959-968

4. Van Bleek CM, Nathenson SC: Isolation of an endogenously processed immunodominant viral peptide from the class I $\mathbf{H}$ $2 K^{b}$ molecule. Nature 1990, 348:213-216.

5. Bjorkmann PJ, Saper MA, Samraoui B, Bennett WS, Strominger IL Wiley DC: Structure of the human class I histocompatibility antigen, HLA-A2. Nature 1987, 329:506-512.

6. Bjorkmann PJ, Saper MA, Samraoui B, Bennett WS, Strominger H. Wiley DC: The foreign antigen binding site and $\mathrm{T}$ cell recognition regions of class I histocompatibility antigens. Nature 1987 329:512-518

7. Kast WM, Roux L, Curren J, et af.: Protection against lethal Sendai virus infection by in vivo priming of virus-specific cytotoxic T lymphocytes with a free synthetic peptide. Proc Nat Acad Sci USA 1991, 88:2283-2287.

8. Morrison \&. Elvin J, Latron F, Gotch F, Moots R, Strominger Jl, McMichael A: Identification of the nonamer peptide from influenza A matrix protein and the role of pockets of HLA-A2 in its recognition by cytotoxic $\mathrm{T}$ lymphocytes. Eur / Immunol 1992, 22:903-907.

9. Schulz $M$, Zinkernagel $R M$, Hengartner $H$ : Peptide induced antiviral protection by cytotoxic T cells. Proc Natl Acad Sci USA 1991, 88:991-993.

10. van Balen CA, Klein MR, Geretti AMt of al: Selective in vitro expansion of HLA class I-restricted HIV-1 Gag-specific CD8+ T cells: cytotoxic T-lymphocyte epitopes and precursor frequencies. AlDS 1993, 7:781-786.

11. Nixon DF, McMichael AJ: Cytotoxic T-cell recognition of HIV proteins and peptides. AIDS 1991, 5:1049-1059

12. Clerici M: Cell-mediated immunity in HIV infection. AIDS 1993, 7 (supol 1):\$135-\$140.

13. Venet A, Walker BD: Cytotoxic T-cell epitopes in HIV/SIV infection. AIDS 1993, 7 (suppl 1):S117-S126.

14. Miedema F, Petit AIC, Terpstra FG, et al: Immunological abnormalities in human immunodeficiency virus (HIV) infected asymptomatic homosexual men. HIV affects the immune sys- tem before CD4+ T-helper cell depletion occurs. I Clin Invest $1988,82: 1908-1914$.

15. Gruters RA, Terpstra FG, De Jong $R$, Van Noesel CIM, Van Lier RAW, Miedema F: Selective loss of T-cell functions in different stages of HIV infection. Eur / Immuno' 1990, 20:1039-1044

16. Terpstra FG, Al BIM, Roos MThL, et al.: Longitudinal study of leukocyte functions in homosexual men seroconverted for HIV rapid and persistent loss of B-cell function after HIV infection. Eur f Immunol 1989, 19:667-673.

17. Pantaleo G. De Maria A, Koenig S, et al: CD8+ T lymphocytes of patients with AIDS maintain normal broad cytolytic function despite the loss of human immunodeficiency virus-specific cytotoxicity. Proc Natl Acad Sci US.A 1990, 87:4818-4822.

18. Walker CM, Moody DI, Sittes DP, Lewy JA: CD8+ lymphocytes can control HIV infection in vitro by suppressing virus replication. Science 1986, 234:1563-1566.

19. Tsubota $\mathrm{H}$, Lard $\mathrm{Cl}$ Watkins $\mathrm{DI}$ Morimoto $\mathrm{C}$, Letvin NL: A cytotoxic $T$ lymphocyte inhibits acquired immunodeficiency syndrome virus replication in peripheral blood lymphocytes. J Exp Med $1989,169: 1421-1434$

20. Venet A, Bourgault I, Aubertin AM, Kieny MP, Levy IP: Cytotoxic T-lymphocyte response against multiple simian immunodeficiency virus (SIV) proteins in SIV-infected macaques. J Immunol 1992, 148:2899-2908.

21. Miller $\mathrm{MD}$, Lord $\mathrm{Cl}$, Stallard $\mathrm{CP}$ Letvin $\mathrm{NL}$ : The gag-specific cytotoxic $\mathrm{T}$ lymphocytes in rhesus monkeys infected with the simian immunodeficiency virus of macaques. I Immunol 1990, 144:122-128

22 Littaua RA, Oldstone MBA Takeda $A$ et al: An HLA-C restricted $\mathrm{CDB}+$ cytotoxic T-lymphocyte clone recognizes a highly conserved epitope on human immunodeficiency virus type 1 gag. / Virol 1991, 65:4051-4056.

23. Klein MR, Bende RJ, Van Baalen CA Keet IPM, Feftinck-Schattenkerk JKM. Miedema F: Persistent high gag CTLp frequency and low viral load in long-term asymptomatic HIV infection. IX International Conference on AIDS. Berlin, June 1993 [abstract WS-B03-31.

24. Harrer $E$, Harrer $T$ Buchbinder S, Yilma $T$, Johnson RP, Walker BD: HIV-specific CTL response in healthy long-term seropositive persons. IX international Conference on AIDS. Berlin, June 1993 [abstract PO-A22-484].

25. Koenig S, Fuerst TR, Wood LV, et al: Mapping the fine specificity of a cytolytic $T$ cell response to HIV-1 nef protein. I Immunol 1990, 145:127-135.

26. Ratner L: Molecular biology and pathogenesis of HIV infection. Curt Opin Infect Dis 1993, 6:181-790.

27. MCNearney T, Hornickova Z, Markham R, et al.: Relationship of human immunodeficiency virus type 1 sequence heterogeneity to stage of disease. Proc Natl Acad Sci USA 19192. 89:10247-10251.

28. Phillips RE, Rowland-Jones S, Nixon DF, et al.: Human immunodeficiency virus genetic variation that can escape $\mathrm{cy}$ totoxic $T$ cell recognition. Nature 1991, 354:453-459.

29. Dai L, West K, Littaua R, Takahashi K, Ennis F: Mutation of human immunodeficiency virus type 1 at amino acid 585 on gp41 results in loss of killing by CD8 + A24-restricted cytotoxic T lymphacyte. / Virol 1992, 66:3151-3154.

3.0. Johnson RP, Trocha A, Buchanan TM, Walker BD: Identification of overlapping HLA class I-restricted cytotoxic T-cell epitopes in a conserved region of the human immunodeficiency virus type 1 envelope glycoprotein: definition of minimum epitopes and analysis of the effects of sequence variation. I Exp Med 1992, 175:961-971.

31. Imanishi T. Akaza T, Kimura A et al: Allele and haplotype frequencies for HLA and complement loci in various ethnic groups. In HLA 1991. Proceedings of the Eleventh International Histocompatibility Workshop and Conference. Edited by Tsuji K, Aizawa M, Sasazuki T. Tokyo: Oxford University Press; 1992:1066-1077.

32. Macatonia SE, Taylor PM, Knight SC, Askonas BA: Primary stimulation by dendritic cells induces antiviral proliferative and cytotoxic T-cell responses in vitro. I Exp Med 1989, 169:1255-1264.

33. De Bruijin MLH Schumacher TNM Nieland ID, Ploegh HL Kast WM, Melief CJM: Peptide loading of empty MHC molecules on RMA-S cells allows induction of primary crtotoxic Iymphocyte responses. Eur / Immunol 1991, 21:2963-2970.

34. Houbiers JGA, Nijman HW, Van Der Burg $\mathrm{SH}$, et al.: In vitro induction of human cytotoxic T-Jymphocyte responses against 
peptides of mutant and wild-type p53. Eur / immunal 1993, 23:2072-2077.

35. Salter RD, Creswell P: Impaired assembly and transport of HLA-A and -B antigens in a mutant TxB cell hybrid. EMBO ) $1986,5: 943-949$

36. Nijman HW, Houbiers JGA, Vierboom MPM, et al.: Identification of peptide sequences that potentially trigger HLA. A2.1 restricted cytatoxic $T$ lymphocytes. Eur / Immunol 1993, 23:1215-1219.

37. Flexner C. Broyles SS, Earl P, Chakrabarti S, Moss B: Characterization of human immunodeficiency virus gag/pol gene products expressed by recombinant vaccinia viruses. Virology 1988, 166:339-349

38. Chakrabarti S, Brechling $K$, Moss B: Coexpression of $\beta$ galactosidase provides visual screening of recombinant virus plaques. Mol Cell Biol 1985, 5:3403-3409.

39. Horai S, Van De Poel J, Goulmy E: Differential recognition of the serologically defined HLA-A2 antigen by allogeneic cytotoxic $\mathrm{T}$ cells. Immunogenetics 1992, 16:135-142.

40. Koning $F$, Kardol $M$, Van De Poel $J$, et al: The influence of the workshop monoclonal antibodies on CML, AgTR, PLT, ADCC and NK cell activity. Functional studies with workshop antibodies. In Proceedings of the Second International Workshop on Human Leucocyte Differentiation Antigens. Fdited by Reinherz EL, Haynes BF, Nadler LM, Bernstein LD. Heidelberg: Springer; 1986:189-203.

41. Myers G, Wain-Hobson S, Korber B, Smith RF, Pavlakis GN (Eds): $A$ compilation and analysis of nucleic acid and amino acid sequences. In Human Retroviruses and AIDS (vol 1-11). LoS Alamos: Los Alamos National Laboratory; 1993 (section 11).

42. Walker BD, Flexner $C$, Birch-Limberger $K$, et al:. Long term culture and fine specificity of human cytotoxic $T$ lymphocyte clones reactive with human immunodeficiency virus type 1 . Proc Natl Acad Sci USA 1989, 86:9514-9518.

43. Johnson RP, Trocha A, Yang L, et al: HIV-1 gag-specific cytotoxic T-lymphocyte clones recognize multiple highly conserved epitopes. I Immunol 1991, 147:1512-1521.

44. Melief CIM, Kast W/M: Lessons from T-cell responses to virusinduced tumours for cancer eradication in general. Cancer Surv 1992, 13:81-99.

45. Hammond SA, Bollinger RC, Stanhope PE, et al: Comparative clonal analysis of human immunodeficiency virus type 1 (HIV-1)-specific CD4+ and CD8+ cytolytic T lymphocytes isolated from seronegative humans immunized with candidate HIV-1 vaccines. / Exp Med 1992, 176:1531-1542.

46. Orentas RJ, Hildreth JEK, Obah E, et al:: Induction of CD4+ human cytolytic $T$ cells specific for HIV-infected cells by gp160 subunit vaccine. Science 1990, 248:123.4-1237.

47. DeMaria A, Pantaleo G, Schnittman SM, ef al:: Infection of CD8+ T lymphocytes with HIV: requirement for interac tion with infected $\mathrm{CD} 4+$ cells and induction of infectious virus from chronically infected CD8 + cells. I Immunol 1991, $146: 2220-2226$.

48. DeMaria A, Colombini 5, Schnittman SM, et al: CD8+ Cytolytic $\mathrm{T}$ lymphocytes become infected in vitro in the process of killing HIV-1 infected target cells. Eur / Immunol 1994, 24:531-536.

49. Schnittman SM, Psallidopoulos MC, Lane $\mathrm{HC}$ et al:: The reservoir for HIV-1 in human peripheral blood is a $T$ cell that maintains expression of CD4. Science 1989, 245:305-308.

50. Louwagie 1, MCCutchan FE, Peeters $M$, et al:: Phylogenetic analysis of gag genes from 70 international HIV-1 isolates provides evidence for multiple genotypes. AIDS 1993, 7:769-780.

51. De Bruijn MLH, Nieland JD, Schumacher TNM, Ploegh HL, Kast WM. Melief CIM: Mechanisms of induction of primary virus-specific cytotoxic $\mathrm{T}$ lymphocyte responses. Eur $\int$ Immunol 1992, 22:3013-3020.

52. Celis $E$, Tsai $V$, Crimi $C$, et al: induction of anti-tumor cytotoxic $T$ lymphocytes in normal humans using primary cultures and synthetic peptide epitopes. Proc Natl Acad Sci USA 1994, 91:2105-2109.

53. Feltkamp MCW, smits HL, Vierboom MPM, et al:: Vaccination with cylotoxic T Iymphocyte epitope-containing peptide protects against a tumor induced by human papillomavirus type 16-transformed cells. Eur / Immunol 1993, 23:2242-2249.

54. Larder BA, Purifoy DIM, Powell KL, Darby G: Site-specific mutagenesis of AIDS virus reverse transcriptase. Nature 1987, 327:716-717.

55. Gotch FM, MCMichael AJ. Rothbard I: Recognition of influenza matrix protein by HLA-A2-restricted cytotoxic T lymphocytes: use of analogues to orientate the matrix peptide in the HLA-A2 binding site. / Exp Med 1988, 168:2045-2057.

56. Pircher $H$, Moskophidis $D$, Rohrer $U$, Bürki $K$, Hengartner $H$, Zinkernagel RM: Viral escape by selection of cytotoxic $T$ cellresistant virus variants in vivo. Nature 1990, 346:629-633.

57. Wakefield $J K$, Jablonski SA, Morrow $C D$ : in vitro enzymatic activity of human immunodeficiency virus type 1 reverse transcriptase mutants in the highly conserved YMDD amino acid motif correlates with the infectious potential of the proviral genome. / Virol 1992, 66:6806-6812.

58. Sijts AJAM, De Bruijn MLH, Ressing ME, et al:- Identification of a $\mathbf{H}-2 \mathbf{K}^{\mathrm{b}}$-presented Moloney murine leukemia virus cytotoxic T-lymphocyte epitope that displays enhanced recognition in H-2Db mutant bm-13 mice. I Virol 1994, 68:6038-6046.

59. Miller MD, Gould-Fogerite S, Shen L, et al.: Vaccination of rhesus monkeys with synthetic peptide in a fusogenic proteoliposome elicits simian immunodeficiency virus-specific $\mathrm{CD} 8+$ cytotoxic T lymphocytes. J Exp Med 1992, 176:1739-1744. 